\title{
С.М. Савушкин
}

\section{ПЕРСПЕКТИВЫ ТРАНСФОРМАЦИИ СИСТЕМЫ И СТРУКТУРЫ ИСПРАВИТЕЛЬНЫХ УЧРЕЖДЕНИЙ}

\begin{abstract}
Рассматриваются тенденции изменения структуры исправительных учреждений в направлении их гибридизации. Продолжающаяся трансформация исправительных учреждений может привести к ликвидации отдельных видов исправительных учреждений. В условиях создания изолированных участков различных видов на территории исправительных учреждений будет происходить улучшение правового статуса осужденных в направлении обеспечения их безопасности и увеличения вероятности отбытия наказания на территории субъекта, где они проживали или были осуждены.
\end{abstract}

Ключевые слова: виды исправительных учреждений, структура исправительных учреждений, дифференцииация осужденных.

В исправительных учреждениях (далее - ИУ) уголовно-исполнительной системы Российской Федерации (далее - УИС РФ) происходят количественные и качественные изменения состава осужденных. Гуманизация уголовного законодательства способствует тому, что наименее опасную часть преступников осуждают к наказаниям, не связанным с изоляцией от общества, как это и должно быть, по нашему мнению. По данным всемирной тюремной интерактивной информационной базы данных Россия по состоянию на 01.08.2016 г. занимала десятое место по числу осужденных к лишению свободы на душу населения (Institute for Criminal Policy Research. http://www.prisonstudies.org). Десять лет назад в мировом рейтинге мы занимали вторую позицию (World Prison Population List http://www. webcitation.org/6183crMfV).

В 2007 г. в учреждениях уголовно-исполнительной системы содержалось 883,4 тыс. человек, в 2012 г. - 701,9 тыс. человек, а по состоянию на 1 января 2017 г. - 630,1 тыс. человек.

В 2015 г. общее число зарегистрированных преступлений среди лиц, содержащихся в местах лишения свободы, составило 940. В воспитательных колониях (далее - ВК) совершено 5 преступлений, в тюрьмах - 2, в следственных изоляторах (далее СИЗО) - 90, в помещениях, функционирующих в режиме следственного изолятора (далее - ПФРСИ), - 5. Основная часть совершенных преступлений в УИС приходится на исправительные колонии (далее ИК) - 838. Уровень преступлений среди осужденных, содержащихся в ИК ФСИН России, в расчете на 1000 человек составил 1,59.

В.А. Уткин отмечает, что на сегодняшний день происходят существенные изменения в структуре контингента осужденных в исправительных колониях для взрослых [1, с. 12]. Доля осужденных к лишению свободы в 2 раза и более увеличилась с $52 \%$ в 2003 г. до 63 \% в 2015 г. При этом последовательно снижается удельный вес осужденных молодежного возраста (18-25 лет). Если в 2010 г. она составляла примерно 23,4 \% всех осужденных в исправи- тельных колониях, то в 2013 г. - 18,9\%, а в $2015 \%$ - всего 16,2 \%. За убийства из числа отбывающих наказание в исправительных колониях в 2003 г. было осуждено $15,8 \%$ человек, в 2010 г. - 24,7\%, в 2015 г. - 27,5\%. Возрастает общее число и удельный вес отбывающих наказание за преступления, связанные с наркотиками: в 2003 г. - 9,7\% всех осужденных; в 2010 г. - 17,9\%; в 2015 - 25,6\%.

Также хотелось бы сказать и о динамике изменения численности осужденных, содержащихся в воспитательных колониях. Так, по состоянию на 2015 г. в воспитательных колониях содержалось 1683 осужденных, что на 5,4 \% меньше, чем АППГ - 1779. Было совершено 5 преступлений, 2 - дезорганизация (одно совершено по ч. 3. ст. 321 УК РФ). Также было 27 попыток дезорганизации, 10 попыток захватов заложников и 72 попытки побега, которые были предотвращены, а общее число предотвращенных преступных намерений, деяний составило 720 при наличии 770 осужденных, состоящих на профилактическом учете.

В.И. Селиверстов отмечает, что в зависимости от характера и тяжести совершенных преступлений, а также поведения в местах лишения свободы уголовно-исполнительный кодекс РФ (далее - УИК РФ) выделяет 22 категории осужденных, имеющих различное правовое положение. При присоединении к этому числу осужденных, которые должны содержаться отдельно или раздельно от других категорий, данное число категорий достигает сорока. Дальнейшая дифференциация осужденных, по его мнению, будет связана со значительными материальными затратами и может повлечь сокращение социально полезных связей осужденных с семьей и другими категориями граждан [2, с. 18]. С этим сложно поспорить, так как на данный момент указанное число категорий требует значительных материальных затрат, что особенно заметно в период оптимизации бюджетных расходов.

Механизм распределения осужденных по ИУ нуждается в совершенствовании. Он будет заключаться в том числе и в пересмотре категорий осуж- 
денных, которые должны содержаться изолированно друг от друга. Уже на сегодняшний день закрепленные положения ст. 74 в процессе отбывания наказания могут пересматриваться. Сначала исправительная колония общего или строгого режима, а позже по ходатайству администрации ИУ суд может перевести осужденного в колонию-поселение или при признании его злостным нарушителем установленного порядка отбывания наказания перевести в тюрьму. А ведь далеко не всех переводят в тюрьму после признания их злостными нарушителями.

Одним из оснований дифференциации осужденных в исправительных учреждениях можно выделить факт постановки осужденного на профилактический учет. На 1 октября 2016 г. на профилактическом учете исправительных колоний территориальных органов УИС состояло 83171 осужденных, из них: 40,13\% - склонных к суициду и членовредительству; 25,96 \% - склонных к посягательствам на половую свободу и половую неприкосновенность; $13,21 \%$ - склонных к употреблению и приобретению наркотических веществ, психотропных средств, сильнодействующих препаратов и алкогольных напитков; 8,44 \% - склонных к совершению побега; $7,85 \%$ - склонных к систематическому нарушению правил внутреннего распорядка; 6,26 \% - склонных к нападению на представителей администрации и иных сотрудников правоохранительных органов (Основные показатели деятельности уголовноисполнительной системы ФСИН России. Январьдекабрь 2015 г. / Информационно-аналитический сборник. Тверь, 2016. С. 32).

Повторное нарушение установленного порядка отбывания наказания является основанием для признания осужденного злостным нарушителем установленного порядка отбывания наказания. Данная часть осужденных представляет небольшую часть осужденных к лишению свободы, но довольно криминогенно опасную, что позволяет констатировать о необходимости содержания определенной их части отдельно от общей массы осужденных.

В.Е. Южанин предлагает оставить ПКТ в качестве меры взыскания, а ЕПКТ определить иное назначение - меры безопасности [3, с. 11]. Нам представляется, что указанное предложение могло бы улучшить ситуацию, если бы не факт того, что не во всех регионах в ЕПКТ обеспечивается должная изоляция.

По нашему мнению, необходимо законодательное закрепление изменений, согласно которым категорию осужденных состоящих на профилактическом учете как лидеры или активные участники группировок отрицательной направленности, возможно в рамках реализации мер безопасности переводить в строгие условия содержания.

По состоянию на 01.01.2016 г. 20596 осужденных находилась в запираемых помещениях для содержания осужденных в строгих условиях отбывания наказания, водворенных в ШИЗО, переведенных в ЕПКТ, ПКТ, одиночную камеру колонии особого режима (Основные показатели деятельности уголовно-исполнительной системы ФСИН России. Январь-сентябрь 2015 г. Информационно-аналитический сборник. Тверь, 2016. С. 17).

Однако сохраняется проблема обеспечения личной безопасности осужденных в связи с противоправными действиями, а также негативным влиянием лидеров и членов группировок криминально ориентированных осужденных и злостных нарушителей установленного порядка отбывания наказания. Так, в Федеральной целевой программе «Развитие уголовно-исполнительной системы 2017-2025 годы» отмечается, что только в 12 субъектах РФ имеющиеся единые помещения камерного типа позволяют обеспечить эффективную изоляцию указанных лиц от основной массы осужденных (Развитие уголовно-исполнительной системы (2017-2025 годы) : Распоряжение Правительства РФ от 23.12.2016 г. № 2808-p // http://www.pravo.gov.ru).

В уголовно-исполнительной классификации ИУ прежде всего выделяется четыре вида, а в дальнейшем законодатель определяет подвиды исправительных колоний (колонии-поселения, исправительные колонии общего, строгого и особого режимов).

По мнению В.А. Уткина, основанному на анализе авторитетных международных документов, вид учреждения, в сущности, определяется двумя критериями: 1) качественно отличной степенью (мерой) изоляции от общества и 2) способами внутреннего организационно-пространственного размещения осужденных (общежития либо камеры). С этих позиций во всяком случае следует разделять по первому критерию так называемые «открытые» и «закрытые» учреждения, а по второму (среди «закрытых») - исправительные колонии (с размещением осужденных в общежитиях) и тюрьмы (с камерным содержанием той или иной степени строгости). Такой подход продемонстрирован, в частности, в ст.ст. 9, 60, 62 Минимальных стандартных правил обращения с заключенными. С учетом этой градации в России, впрочем, как и за рубежом, фактически существует всего три вида учреждений: «открытые» (исправительные колонии-поселения), «закрытые» (охраняемые исправительные и воспитательные колонии) и тюрьмы (которые, как известно, в лексиконе осужденных именуются как «крытые»).

Минимальные стандартные правила обращения с заключенными (ст. 8) высказывались на этот счет предельно конкретно, не отдавая предпочтения ни одному из вариантов: «Различные категории заключенных содержатся в различных заведениях или в разных частях того же заведения с учетом их пола, возраста, предшествующей судимости, юридических причин их заключения и предписанного обращения с ними.

Статистические данные о численности осужденных, содержащихся в воспитательных колониях, а также сложность транспортной логистики говорят о необходимости обсуждения перспектив отбывания 
наказания данной категории осужденных в локальных участках исправительных колоний общего режима. Данные изменения могут относиться и к бывшим сотрудникам правоохранительных органов и судов.

В 2009 г. осужденный В.П. Кирильчук, до привлечения к уголовной ответственности проживавший и работавший в Самарской области, как бывший сотрудник правоохранительных органов был направлен для отбывания наказания в специализированное исправительное учреждение Республики Мордовия. В. П. Кирильчук считал, что такое перемещение нарушает его права, в частности, является причиной изменения привычных климатических условий, разрыва социальных связей, а также создает трудности для реализации права на юридическую помощь, поскольку его представитель проживает в том же регионе, где ранее проживал он сам. Конституционный Суд РФ, изучив представленные им материалы, не нашел оснований для принятия его жалобы к рассмотрению. Но перечисленные аргументы осужденным могут являться маленьким камнем в основе пересмотра ч. 3 ст. 80 УИК РФ в части возможности отбывания наказания данной категорией осужденных в локальных участках исправительных колоний, расположенных на территории субъектов, где они были осуждены.

В долевом соотношении количества осужденных, содержащихся в различных видах ИУ, доминирующее место занимают исправительные колонии строгого режима $(54,3 \%)$, исправительные колонии общего режима занимают второе место $(26,8$ \%), во всех остальных видах исправительных учреждений осужденных содержится не более $6 \%$ (Основные показатели деятельности уголовно-исполнительной системы ФСИН России. Январь-декабрь 2015 г. Информационно-аналитический сборник. Тверь, 2016. С. 7).

На сегодняшний день возможна трансформация структуры исправительных учреждений в направлении объединения нескольких учреждений под общим периметром (общей охраной) и как следствие уменьшение служб охраны. Речь идет не о повсеместной практике объединения учреждений, а учреждениях, архитектоника которых позволяет проводить данные изменения. Данный опыт необходимо учитывать при строительстве новых учреждений, исполняющих наказание в виде лишения свободы. На сегодняшний день данный опыт используется в 7 исправительных колониях, 3 воспитательных колоний и 18 следственных изоляторов, которые находятся на территории и под охраной других учреждений (Основные показатели деятельности уголовноисполнительной системы ФСИН России. Январьдекабрь 2015 г. Информационно-аналитический сборник. Тверь, 2015 г. С. 315). В какой-то мере два учреждения, находящихся под периметром одного учреждения, можно считать одним ИУ с разными видами режима.
Согласно действующему законодательству, в исправительных колониях могут создаваться изолированные участки с различными видами режима, а также изолированные участки, функционирующие как тюрьма. На сегодняшний день пенитенциарная система России включает в себя 8 тюрем. Количество содержащихся в них лиц, которые отбывают наказание, 1705.

Очередным шагом трансформации исправительных учреждений является возможность создания на территории ИУ транзитно-пересыльных пунктов (далее - ТПП). Порядок создания, функционирования и ликвидации транзитно-пересыльных пунктов при ИУ и СИЗО УИС определяется приказом МЮ России от 22.08.2014 г. № 179 «Об утверждении Порядка создания, функционирования и ликвидации транзитно-пересыльных пунктов при исправительных учреждениях и следственных изоляторах уголовно-исполнительной системы». ТПП имеют тюремные начала в части содержания осужденных в камерах.

С 1 января 2017 г. допускается создание исправительных центров в качестве изолированных участков в структуре ИУ, и данное новшество является очередным этапом в трансформации ИУ. Исправительные центры исполняют уголовные наказания в виде принудительных работ. В отдельных случаях возможны случаи, когда осужденные к принудительным работам будут пересекаться с осужденными к лишению свободы, которым разрешено передвижение без конвоя или сопровождения за пределами ИУ.

Изменения структуры и системы ИУ определяются реалиями времени и оказывают существенное влияние на развитие института дифференциации осужденных к лишению свободы. Необходимо комплексно анализировать перспективы реализации международных стандартов исполнения наказания в виде лишения свободы, учитывать географические особенности РФ, от которых в большой степени зависит транспортная логистика (конвоирование осужденных и свидания с родственниками).

В отношении отдельных ИУ, количество осужденных в которых значительно меньше установленного лимита наполнения, проводятся мероприятия, направленные на их ликвидацию и перепрофилирование (изменение типов учреждений, видов режима). Закрытию в первую очередь подлежат исправительные учреждения со значительным износом основных фондов, с ветхими и аварийными зданиями, в которых отсутствует производственная база для трудоустройства осужденных, исправительные учреждения, находящиеся в зонах подтопления, а также расположенные на значительном расстоянии от областных центров. В 2011 г. было ликвидировано 22 таких исправительных учреждения, в 2012 г. - 12, в 2013 г. -19 , в 2014 г. - 19, в 2015 г. - 15 исправительных учреждений. 
Процесс ликвидации ИУ связан с изменением численности осужденных, а также их физическим устареванием. На балансе учреждений УИС числятся 54457 зданий и сооружений, из которых более $60 \%$ построены в середине XX в. без соблюдения строительных, санитарных и пожарных правил и норм, 19 \% зданий являются деревянными (Развитие уголовно-исполнительной системы (2017-2025 годы): Распоряжение Правительства РФ от 23.12.2016 г. № 2808-p // http://www.pravo.gov.ru).

В определенной мере на структуру ИУ оказывает процентное отношение осужденных, освободившихся из исправительных учреждений без профессии, и числа обученных и обучающихся осужденных, что является показателем государственной программы «Юстиция», утвержденной Постановлением Правительства РФ от 15.04.2014 г. № 312. Разумным продолжением обучения осужденных являются мероприятия, направленные на трудоустройство 100 тыс. осужденных. Данное мероприятие предусматривается концепцией Федеральной целевой программы «Развитие уголовно-исполнительной системы (2017-2025 годы)».

Одной из целей концепции развития УИС РФ до 2020 г. является совершенствование деятельности учреждений и органов, исполняющих наказания, с учетом международных стандартов и потребностей общественного развития [1, с. 14]. Для достижения поставленной цели необходимо решить одну из задач, направленную на создание условий для постепенного снижения количества осужденных, содержащихся в одном жилом помещении в исправительных учреждениях.

Одним из мероприятий, которое планируется выполнить в процессе реализации концепции, является дифференциация содержания осужденных в зависимости от характера и степени общественной опасности совершенных ими преступлений, поведения во время отбывания наказания, криминального опыта (раздельное содержание впервые осужденных к лишению свободы и ранее отбывавших наказание в виде лишения свободы, расширение оснований направления в колонию-поселение, с одной стороны, и перевода на тюремный режим - с другой). Нам представляется избыточным перечень оснований для перевода в колонию-поселение. Можно исключить из ст. 78 УИК РФ основание, позволяющее переводить положительно характеризующихся осужденных (за особо тяжкие преступления) из исправительных колоний строгого режима в колониюпоселение. Первая причина такого преступления обосновывается большой разницей между осужденными по совершенному преступлению в соответствии с основами классической школы уголовного права, а вторая - законодатель позволяет использовать социологическую школу при переводе, что видится заманчивым приемом, но не совсем верным.
Минимальные стандартные правила Организации Объединенных Наций в отношении обращения с заключенными (Правила Манделы) требуют индивидуального подхода к заключенным, а следовательно, и наличия гибкой системы их классификации. Отмечается, что группы заключенных рекомендуется помещать в отдельных тюремных учреждениях, подходящих для работы с каждой из них. Одинаковые меры охраны для каждой группы являются не обязательным условием для учреждений такого типа. В зависимости от групп заключенных желательно градуировать строгость этих мер. Одной из целей Правил Манделы является отделение заключенных от тех, кто в силу своего преступного прошлого или своих черт характера грозит оказать на них плохое влияние. Фактически Правила рекомендуют проводить прогнозирование возможного противоправного поведения заключенного на основе определенных критериев, в том числе и черт характера. Представляется актуальным в дальнейших работах проанализировать судебную практику по переводу из исправительных колоний общего и строго режима в колонию-поселение для вычленения критериев, на основании которых осужденных считают положительно характеризующимися и достойными такого перевода.

В Федеральной целевой программе «Развитие уголовно-исполнительной системы (2017-2025 годы)» отмечается, что сложившаяся в настоящая время система исправительных учреждений и их территориальное расположение не позволяют в полном объеме осуществить законодательно закрепленный принцип отбывания осужденными наказания в ИУ в пределах территории субъекта РФ, в котором они проживали или были осуждены (Развитие уголовно-исполнительной системы (2017-2025 годы): Распоряжение Правительства РФ от 23.12.2016 г. № 2808-p // http://www.pravo.gov.ru).

Хотелось бы отметить, что данное требование не является правовым принципом. Данное положение закреплено в ст. 73 УИК РФ. В данном случае отсутствует необходимость ровняться на Европу в контексте географических особенностей и плотности населения. В России на один субъект Федерации приходится 1,75 млн жителей (без учета Москвы и Московской области, в указанных двух субъектах проживает около 20 млн человек), а, например, в США и Бразилии на один субъект приходится примерно по 5 млн человек, т.е. больше, чем у нас, в 2,5-3 раза. Общее количество субъектов у нас на сегодняшний день 85 , в то время как в Бразилии - 27, Германии - 16, Индии - 36, в США - 50. В тринадцати субъектах РФ население меньше 500 тыс. человек. Создавать в каждом из них все виды исправительных учреждений не представляется разумным.

Н.В. Бозо и Г.В. Михеева отмечают, что в настоящее время существует необходимость глубокого реформирования всей административно-террито- 
риальной организации России с изменением характера и масштаба ее звеньев, прежде всего основных, поскольку они малопригодны для налаживания действенного государственного управления в условиях рыночной экономики [4, с. 191]. При объединении субъекта РФ, в котором отсутствуют отдельные исправительные учреждения с субъектом РФ, где такие проблемы отсутствуют, автоматически в двух регионах пропадут нарушения ст. 73 УИК РФ в части отбывания наказания в пределах территории субъекта РФ, в котором осужденные проживали или были осуждены.

По мнению В.Е. Южанина, необходимо, чтобы групповая дифференциация и распределение осужденных в ИУ осуществлялась с учетом меняющейся структуры пенитенциарных учреждений, в которых могут создаваться различные изолированные участки с содержанием в них разного контингента осужденных [5, с. 14].

Можно отметить этапы трансформации:

- в 2001 г. появилась возможность создания в одной исправительной колонии изолированных участков с различными видами режима;

- в 2003 г. появилась возможность создания в воспитательных колониях изолированных участков, функционирующих как исправительные колонии общего режима;
- в 2012 г. для временного содержания осужденных, следующих к месту отбывания наказания либо перемещаемых из одного места отбывания наказания в другое, при исправительных учреждениях и следственных изоляторах стали создаваться транзитно-пересыльные пункты;

- в 2013 г. в исправительных колониях разрешили создавать изолированные участки, функционирующие как тюрьма;

- с 1 января 2017 г. разрешено создавать изолированные участки, функционирующие как исправительные центры при исправительных учреждениях.

В заключение можно констатировать, что опыт трансформации исправительных учреждений в направлении развития тюремных начал и гибридизации является положительным. Имеется необходимость ликвидации воспитательных колоний и пересмотра положений, направленных на конвоирование осужденных бывших сотрудников правоохранительных органов и судов в отдельные исправительные учреждения, расположенные в определенных субъектах, а взамен создавать изолированные участки в колониях, расположенных в субъектах, где они проживали или были осуждены. Такую трансформацию необходимо проводить с учетом архитектоники исправительных учреждений, которые находятся в удовлетворительном состоянии.

\section{ЛИТЕРАТУРА}

1. Уткин B.A. Судебная практика и уголовно-исполнительная политика // Уголовно-исполнительная политика и вопросы исполнения уголовных наказаний: сб. материалов Междунар. науч-практич. конф. (г. Рязань, 24-25 нояб. 2016 г.): в 2 т. Рязань: Академия ФСИН России, 2016. С. 10-16.

2. Селиверстов В.И. Некоторые направления уголовно-исполнительной политики России на современном этапе // Актуальные вопросы юриспруденции. 2009. № 5. С. 16-20.

3. Южанин B.E. Режимы наказания, обеспечения его отбывания и безопасности в исправительных учреждениях // Человек: преступление и наказание. 2014. № 1 (84). С. 9-12.

4. Бозо Н.В., Михеева Г.В. Влияние изменений в административно-территориальном делении РФ на социальные и экономические показатели // Вестник Томского государственного университета. 2015. № 400. С. 190-197.

5. Южанин В.E. Современные проблемы классификации осужденных и распределения их в исправительном учреждении // Уголовно-исполнительное право. 2015. № 2. С. 14-18.

\section{PROSPECTS OF THE TRANSFORMATION OF THE SYSTEM AND STRUCTURE OF CORRECTIONAL FACILITIES}

Ugolovnaya yustitsiya - Russian Journal of Criminal Law, 2016, 2(8), 64-69. DOI 10.17223/23088451/8/10

Sergey M. Savushkin, Kuzbass Institute of the Federal Penitentiary Service of the Russian Federation (Novokuznetsk, Russian Federation). E-mail: crimjust@mail.ru

Keywords: types of correctional facilities, structure of correctional facilities, differentiation of convicts.

The article examines the trends in the structure of correctional facilities in terms of their hybridization. The ongoing transformation of correctional facilities may lead to the elimination of their separate types. The stages of the transformation of the system and structure of correctional facilities are as following. In 2001, it became possible to make isolated sections with different types of regime in one correctional facility. In 2003, it became possible to make isolated sections in educative colonies that function as correctional colonies of general regime. In 2012, transit points were established in prisons and detention facilities for temporary detention of convicts who are sent to the place of serving punishment or transferred from one place of serving punishment to another. In 2013, correctional colonies were allowed to make isolated sections that function as prisons. From January 1,2017 , it is allowed to establish isolated sections that function as correctional centres at correctional facilities. It can be concluded that the experience of transforming correctional facilities towards prison principles development and hybridization is positive. There is a need to eliminate educative colonies and review provisions on convoying the convicted former law enforcement and court officers to separate correctional facilities located in certain RF subjects, and, in return, to establish isolated sections in colonies located in the RF subjects where such officers lived or were convicted. The transformation must be carried out taking into account the architectonics of correctional facilities that are in a satisfactory condition. 


\section{REFERENCES}

1. Utkin, V.A. (2016) [Judicial practice and the penal policy]. Ugolovno-ispolnitel'naya politika $i$ voprosy ispolneniya ugolovnykh nakazaniy [The penal policy and execution of criminal punishments]. Proc. of the international conference. Ryazan. 24-25 November 2016. Ryazan: Akademiya FSIN Rossii. pp. 10-16. (In Russian).

2. Seliverstov, V.I. (2009) Nekotorye napravleniya ugolovno-ispolnitel'noy politiki Rossii na sovremennom etape [Some directions of the penal policy of Russia at the present stage]. Aktual'nye voprosy yurisprudentsii. 5. pp. 16-20.

3. Yuzhanin, V.E. (2014) Modes of punishment, ensuring its security and serving in prisons. Chelovek: prestuplenie i nakazanie - Man: Crime and Punishment. 1 (84). pp. 9-12. (In Russian).

4. Bozo, N.V. \& Mikheeva, G.V. (2015) Influence of changes in administrative-territorial division of the Russian Federation on social and economic indicators. Vestnik Tomskogo gosudarstvennogo universiteta - Tomsk State University Journal. 400. pp. 190-197. (In Russian).

5. Yuzhanin, V.E. (2015) Modern problems of classification and distribution of prisoners in correctional institutions. Ugolovnoispolnitel'noe pravo-Penal Law. 2. pp. 14-18. (In Russian). 